\title{
A Statistical Optimization of Convective Drying of Corn Kernels in a Fluidized Bed Dryer
}

DOI:10.36909/jer.10775

\author{
Shina Gautam*, Alok Gautam, Bhavik Mahant \\ Department of Chemical Engineering, Shroff S R Rotary Institute of Chemical Technology, \\ Ankleshwar, Gujarat, India 393135. \\ *Email: shinaiitd@gmail.com; Corresponding author.
}

\begin{abstract}
Food storage is an essential process for food security and it needs to be free from any biological contamination. For the same, agriculture produce needs to be completely dried before sending for storage. The present work discusses a systematic approach to model drying parameters of corn kernels in a fluidized bed dryer. Experiments were designed according to a higher level Box-Behnken design combined with response surface methodology. Four parameters were chosen to vary namely: amount of corn kernels (50 -100 gm), temperature of drying $\left(50-80^{\circ} \mathrm{C}\right)$, air velocity $(6.01-8.08 \mathrm{~m} / \mathrm{s})$ and drying time $(30-60 \mathrm{~min})$ for experiments as well as for the model. The reduction of moisture content was determined after each experiment for understanding the behaviour of drying process. The model equations were obtained and surface response plots were generated in MATLAB to investigate the drying behaviour of corn kernels with all four parameters. Ultimately, this work represents the dependence of moisture removal on all four parameters chosen with efficient use of response surface methodology and Box-Behnken design. Analysis of variance confirmed that velocity of air and amount of corn are the most significant parameters along with temperature and time
\end{abstract}


of drying. Optimum condition with the model were obtained as $50 \mathrm{gm}$ of corn kernels, $80{ }^{\circ} \mathrm{C}$ drying temperature, $8 \mathrm{~m} / \mathrm{sec}$ velocity of air, and $60 \mathrm{~min}$ time of drying for $73.3 \%$ of moisture from corn kernels.

Keywords: corn kernels drying, fluidized bed dryer, drying temperature, drying time, amount of feed.

\section{INTRODUCTION}

In food processing, drying is a unit operation removing moisture to a desired extent for various products. Moisture from any food material is indispensable to decrease the activity of microorganism and reducing volume for transfer and storage cost. The most used grain which is corn, has output of starch and protein close to $85 \%$ and $15 \%$, respectively (Malumba et al., 2009). Bio fuel and bio ethanol can be easily converted from corn, it can be an alternate and better renewable source of energy. There are more than 3500 products extracted from corn and it's annual production is over $10 \times 10^{7}$ tons.

Drying of food materials or grains can be done by several means. Sun drying or solar drying is a cheapest and conventional method used in rural areas. However, the efficiency of a conventional drying system is usually low. In food industry drying is done by different dryers. Microwave and vacuum drying are a few of the effective methods to dry a food material however it's implication particularly of microwave at industrial scale is difficult (Nawirska et al., 2009). It is therefore desirable to improve the efficiency of the drying process (Inaba et al., 2002). Thin layer drying in a tray dryer and fluidized bed dryer are widely used process for removal of moisture from food material. Fluidized bed dryers are used extensively for grain drying (Owolade et al., 2004). Due to high energy consumption 
and large amount of moisture present in food material, it is necessary to identify the parameters which affect dryness and specify the optimum condition of use.

The effects process parameters viz. drying air temperature, air flow rate, residence time, and moisture content of grain on some mechanical, chemical, and biological properties were investigated (Zahoor et al., 2016). Optimization of process parameters and feasible process is not only with respect to cost but also with respect to physical parameters is required for operability of corn kernel drying (Nawirska et al., 2009). The fluidized bed dryer is widely used in many industries with several advantages than other types as follows (Nonhebel and Moss, 1971):

(1) Rates of heat and mass transfer are high consequently drying time is short, the dryer is small but high capacity.

(2) Isothermal conditions in fluidized bed makes the quality of the product uniform and easier to run it continuously in controlled conditions.

These advantages can be achieved by high air velocity, from this fact thermal efficiency of fluidized bed dryer might low and thus it is important to get an economic evaluation of drying process (Giner, S. A., Calvelo, 1987).

As per literature available, drying of corn kernels is not addressed properly with all the operating parameters. Due to simultaneous heat and mass transfer it is important to focus certain parameters to minimize energy cost of operation (Sahdev et al., 2017). The present study includes the most important parameter of corn kernel drying in fluidized bed dryer like air velocity, amount of feed, temperature of drying and time of drying. Kinetic models study have been done in literature and different kinetic model and moisture removal has been examined (Soponronnarit et al., 1997 and Zhang and Litchfield, 1991). 
However, responses of individual parameters have not been observed so far. It initiates the need to see individual response on the level of effectiveness for drying of each parameter. Response surface methodology has been applied for the mentioned parameters and BoxBehnken design has been utilised to observe the response of the parameters. A MATLAB code with response surface methodology has been generated and experimental observation were compared with the model equation.

\section{MATERIALS AND METHODS}

Fresh corn was obtained from local vegetable market at Ankleshwar, Gujarat, India. Corn silk and husk were removed manually from corn cobs. After cleaning, a sharp circular knife was used to remove kernels from cobs. Corn kernels were recovered in an appropriate shape without any shrinkage or breakage. Corn kernels were rinsed with distilled water and left for an hour at room temperature for superficial drying. Total moisture present in corn kernels was evaluated by keeping known amount of kernels in an air drying oven at $60^{\circ} \mathrm{C}$ for $2 \mathrm{~h}$. In this time $72 \%$ moisture was removed, the sample was kept again for another 30 min at same temperature however, no change in mass was observed. Therefore, it is considered as total moisture present in corn kernels. Further experimentation of drying was done keeping this as reference moisture or total moisture.

A cylindrical fluidized bed of 500x $260 \mathrm{~mm}^{2}$ laboratory scale was used for experimental study. The schematic diagram is shown in Figure 1 supplied by K C Engineers Ambala, India. A blower followed by a preheater was attached to heat compressed air. A collection box was attached to collect carried over particles from the fluidized bed dryer. Two probes were inserted at inlet and outlet of air to monitor the temperature of hot air. Drying temperature of range $50-80{ }^{\circ} \mathrm{C}$ was used for drying experiments. Air velocity was kept enough so that particles of corn can be fluidized efficiently however, they should not be 
carried over. The range of air velocity was from $6-8 \mathrm{~m} / \mathrm{sec}$. Time of drying was varied from 30 to $60 \mathrm{~min}$.

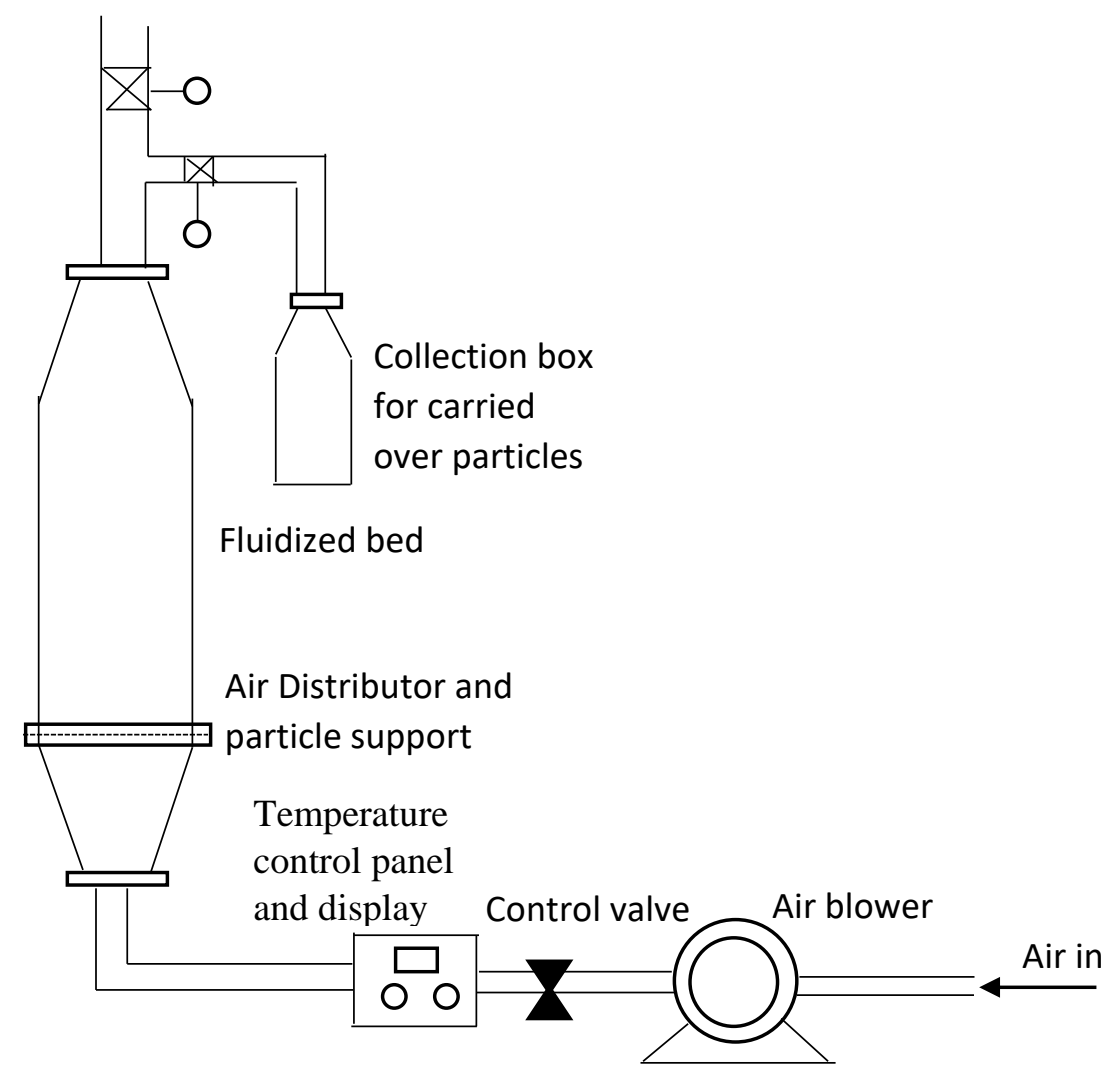

Figure 1 Schematic diagram of laboratory scale fluidized bed dryer.

\section{RESPONSE SURFACE METHODOLOGY}

Response surface methodology (RSM) was used to investigate the main effects of process variables on moisture content. Amount of feed $\left(x_{1}\right)$, drying temperature $\left(x_{2}\right)$, air velocity $\left(x_{3}\right)$, and time of drying $\left(x_{4}\right)$ were selected as independent parameters. A Box-Behnken design method using 27 experiment with 4 parameters formed by 6 central points and 6 axial points to $2^{3}$ full factorial design was used (Mathekar and Agrawal, 2017). Using this 
technique one can evaluate the effect of different important parameters on response. Therefore, these four independent parameters were coded at three levels that is $+1,0$, and -1 with same step size, where +1 represents the maximum value, 0 represents to the center, and 1 represents the minimum value of each parameter which are considered for analysis (Singh et al., 2016 and Momenzadeh et al., 2011). Within the present research framework, the discussion was focused on the effect of amount of feed $\left(x_{1}\right)$, temperature of drying $\left(x_{2}\right)$, velocity of hot air $\left(x_{3}\right)$, and drying time $\left(x_{4}\right)$.

To evaluate the optimum conditions, a model which is quadratic in nature, was used to relate the dryness of corn kernel to independent parameters, Eq.(1):

$$
y=\beta_{0}+\sum_{j=1}^{n} \beta_{j} x_{j}+\sum_{j=1}^{n} \beta_{j j} x_{j}^{2}+\sum_{j=1}^{n-1} \sum_{k=2}^{n} \beta_{j k} x_{j} x_{k}+\delta
$$

The set of regression coefficient $\beta$ 's are unknown and estimated by least squares. In vector matrix, the equation for least square fit is given by:

$$
Y=X \beta+\delta
$$

where, $Y$ is defined as the measured value and $X$ to be a matrix of independent variables. Regression coefficient $\beta$ was evaluated by the non-singular regression matrix transpose $X^{\prime}$.

$$
\begin{gathered}
y_{d}=\beta_{0}+\beta_{1} X_{1}+\beta_{2} X_{2}+\beta_{3} X_{3}+\beta_{4} X_{4}++\beta_{5} X_{1}^{2} \\
+\beta_{6} X_{2}^{2}+\beta_{7} X_{3}^{2}+\beta_{8} X_{4}^{2}+\beta_{9} X_{1} X_{2}+\beta_{10} X_{1} X_{3}+\beta_{11} X_{1} X_{4}+\beta_{12} X_{2} X_{3}+\beta_{13} X_{2} X_{4}+\beta_{14} X_{3} X_{4}+\delta_{i}
\end{gathered}
$$

where $y_{d}$ is response and $X_{1}, X_{2}, X_{3}, X_{4}$ are parameters defined and these are independent. $\beta_{0}$ is the constant coefficient, $\beta_{1}, \beta_{2}, \beta_{3}, \beta_{4}$ are the coefficient for linear effect, $\beta_{5}, \beta_{6}, \beta_{7}, \beta_{8}$ are 
the coefficient for quadratic effect, $\beta_{9}, \beta_{10}, \beta_{11}, \beta_{12}, \beta_{13}, \beta_{14}$ are the coefficient for the interaction effect and $\delta_{i}$ is the error.

$$
\beta=\left(X^{\prime} X\right)^{-1} X^{\prime} Y
$$

where $X^{\prime}$ is the transpose of the matrix $X$ and $\left(X^{\prime} X\right)^{-1}$ is the inverse of the matrix $X^{\prime} X$. Response surface methodology uses the experimental data points of the design matrix to a proposed model and the unknown coefficients. To find the minimum number of experimental run required for Box-Behnken design one can use equation given below:

$$
N=2 N_{f}\left(N_{f}-1\right)+C_{p}
$$

where $N_{f}$ is the number of parameters used to fit the model, and $C_{p}$ is the number of the central points. To evaluate the coefficient values experiments were carried out according to the Box-Behnken design.

\section{RESULTS AND DISCUSSIONS}

Model equations basically represent the relation between dryness and different experimental design parameters. Considering all the parameters namely drying time, air velocity, drying temperature and amount of feed, model equation with Box-Behnken design was obtained as given below (Doymaz, 2009):

$$
\begin{aligned}
& y_{d}=42.69+1.89 X_{1}+1.14 X_{2}-57.62 X_{3}+2.21 X_{4}-0.003 X_{1}^{2}-0.003 X_{2}^{2}+3.485 X_{3}^{2}- \\
& 0.0016 X_{4}^{2}-0.0099 X_{1} X_{2}-0.029 X_{1} X_{3}-0.011 X_{1} X_{4}+0.16 X_{2} X_{3}-0.014 X_{2}+0.073 X_{3} X_{4}
\end{aligned}
$$

Using the parameters defined in Table 1, the experimental values were obtained by performing experiments with different combinations as in Table 2. The predicted values were calculated using Eq. (6). 
Table 1 Level of parameters in Box-Behnken Design.

\begin{tabular}{|l|c|c|c|}
\hline Parameters & Low (-1) & Center (0) & High (+1) \\
\hline$X_{1}$ (Amount of feed, gm) & 50 & 75 & 100 \\
\hline$X\left(\right.$ Temperature $\left.^{\circ}{ }^{\circ} \mathrm{C}\right)$ & 50 & 65 & 80 \\
\hline$X_{3}($ Air velocity, $\mathrm{m} / \mathrm{sec})$ & 6.01 & 7.05 & 8.08 \\
\hline$X_{4}($ Time, $\mathrm{min})$ & 30 & 45 & 60 \\
\hline
\end{tabular}

Table 2 Coded and uncoded design matrix of different parameters.

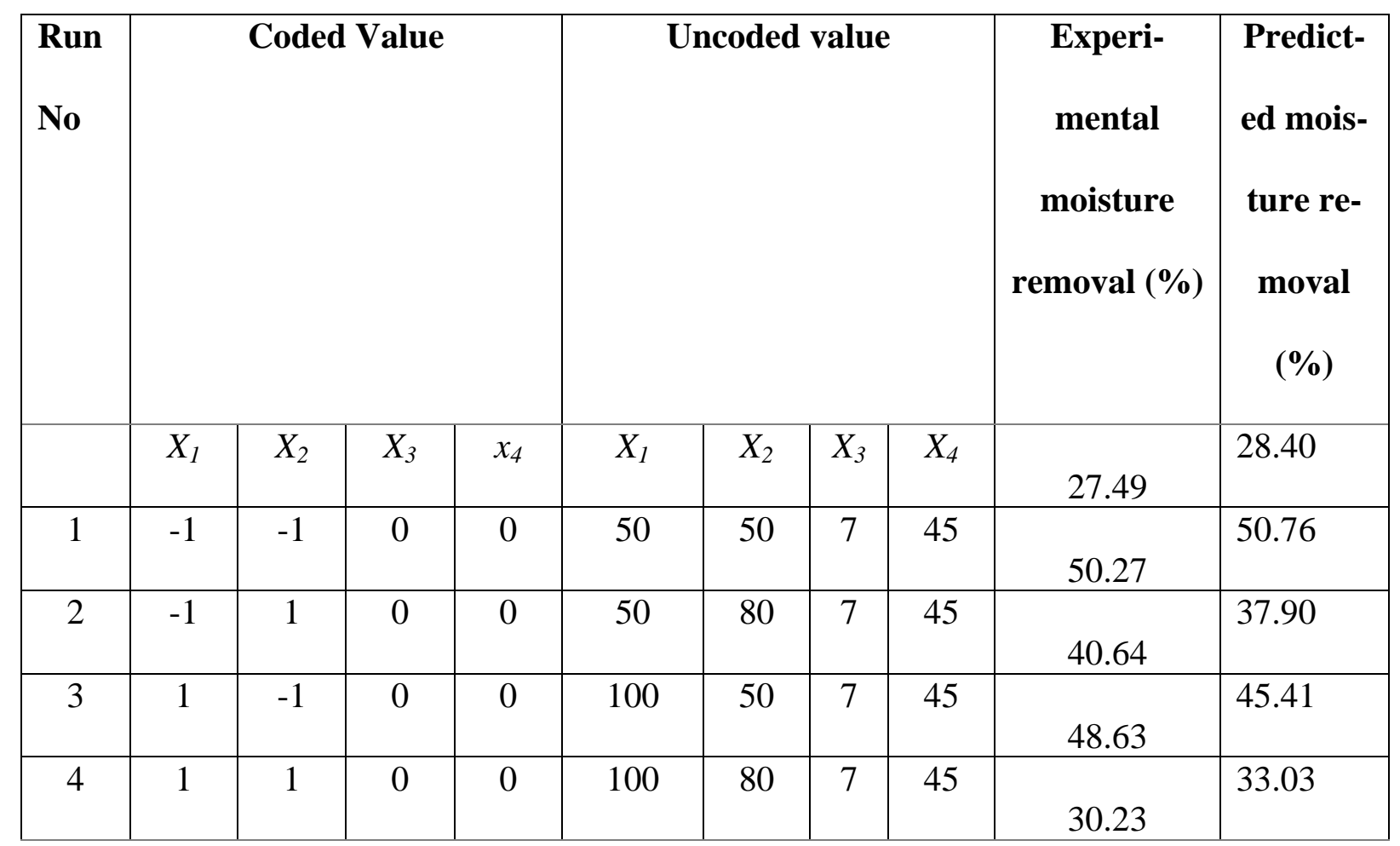




\begin{tabular}{|c|c|c|c|c|c|c|c|c|c|c|}
\hline 5 & 0 & 0 & -1 & -1 & 75 & 65 & 6 & 30 & 57.84 & 54.55 \\
\hline 6 & 0 & 0 & -1 & 1 & 75 & 65 & 6 & 60 & 35.15 & 36.12 \\
\hline 7 & 0 & 0 & 1 & -1 & 75 & 65 & 8 & 30 & 67.15 & 62.02 \\
\hline 8 & 0 & 0 & 1 & 1 & 75 & 65 & 8 & 60 & 24.68 & 23.75 \\
\hline 9 & -1 & 0 & 0 & -1 & 50 & 65 & 7 & 30 & 52.70 & 55.94 \\
\hline 10 & -1 & 0 & 0 & 1 & 50 & 65 & 7 & 60 & 30.02 & 34.30 \\
\hline 11 & 1 & 0 & 0 & -1 & 100 & 65 & 7 & 30 & 41.03 & 49.54 \\
\hline 12 & 1 & 0 & 0 & 1 & 100 & 65 & 7 & 60 & 37.03 & 38.44 \\
\hline 13 & 0 & -1 & -1 & 0 & 75 & 50 & 6 & 45 & 33.82 & 38.95 \\
\hline 14 & 0 & -1 & 1 & 0 & 75 & 50 & 8 & 45 & 46.19 & 48.60 \\
\hline 15 & 0 & 1 & -1 & 0 & 75 & 80 & 6 & 45 & 52.51 & 58.65 \\
\hline 16 & 0 & 1 & 1 & 0 & 75 & 80 & 8 & 45 & 40.73 & 40.33 \\
\hline 17 & -1 & 0 & -1 & 0 & 50 & 65 & 6 & 45 & 49.34 & 47.05 \\
\hline 18 & -1 & 0 & 1 & 0 & 50 & 65 & 8 & 45 & 45.63 & 43.85 \\
\hline 19 & 1 & 0 & -1 & 0 & 100 & 65 & 6 & 45 & 51.36 & 47.69 \\
\hline 20 & 1 & 0 & 1 & 0 & 100 & 65 & 8 & 45 & 22.71 & 19.75 \\
\hline 21 & 0 & -1 & 0 & -1 & 75 & 50 & 7 & 30 & 50.68 & 49.94 \\
\hline 22 & 0 & -1 & 0 & 1 & 75 & 50 & 7 & 60 & 44.53 & 41.17 \\
\hline 23 & 0 & 1 & 0 & -1 & 75 & 80 & 7 & 30 & 59.51 & 58.40 \\
\hline 24 & 0 & 1 & 0 & 1 & 75 & 80 & 7 & 60 & 43.12 & 43.31 \\
\hline 25 & 0 & 0 & 0 & 0 & 75 & 65 & 7 & 45 & 43.12 & 43.31 \\
\hline 26 & 0 & 0 & 0 & 0 & 75 & 65 & 7 & 45 & 43.12 & 43.31 \\
\hline 27 & 0 & 0 & 0 & 0 & 75 & 65 & 7 & 45 & 27.49 & 28.40 \\
\hline
\end{tabular}


Air velocity, at minimum fluidization velocity was taken as minimum value $6.01 \mathrm{~m} / \mathrm{sec}$ and $8.08 \mathrm{~m} / \mathrm{sec}$ was maximum air velocity provided, beyond this velocity the height of the fluidized bed was reached to the top and material started to come out with air. Selected minimum and maximum values were decided based on the experimental set up design. Figure 2 shows the effect of air velocity and amount of feed for moisture removal. Corn kernels were dried more as air velocity was increased for a particular amount of feed. Experiments have been performed on corn drying in fluidized bed dryer and tray dryer, maintaining air velocity $2.5 \mathrm{~m} / \mathrm{sec}$ and $0.45 \mathrm{~m} / \mathrm{sec}$ in fluidized bed dryer and tray dryer, the total moisture contained in the corn was $25 \% .^{[11]}$ The diffusion coefficient observed in fluidized bed dryer was $70 \%$ higher than tray dryer. In view of that, moisture available in corn kernels was higher and more drying time and temperature will be required to bone dry corn kernels.

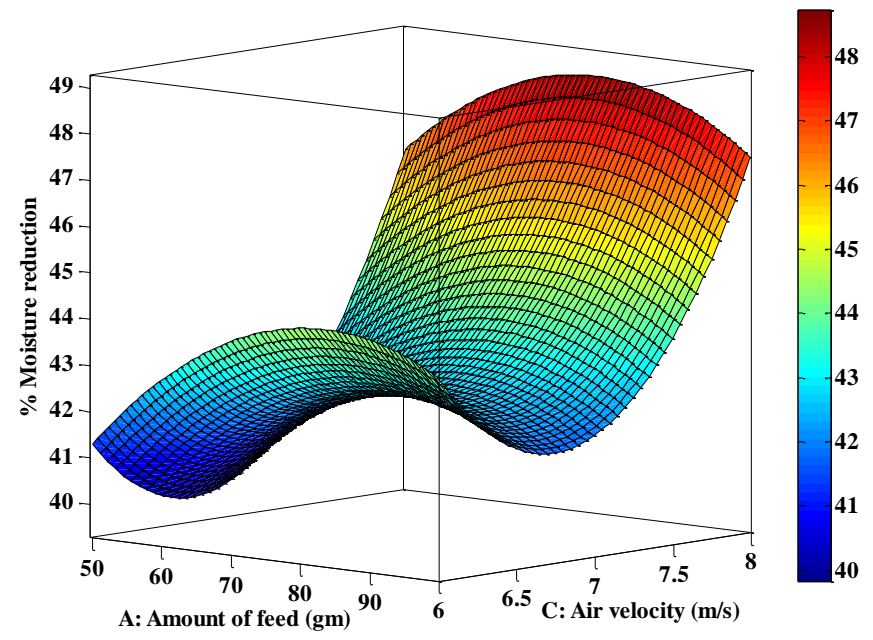

Figure 2 Response of moisture reduction with variation of amount of corn kernels and air velocity.

Figure 3 shows the moisture removal with increasing mass of corn and drying temperature. It is observed that increasing feed and temperature together results in less moisture reduction however, keeping feed amount constant with increasing temperature enhances moisture 
reduction. Figure 4 depicts the effect of feed amount and time of drying on moisture removal. Similar to the previous result, moisture was reduced more when amount of feed was kept constant with increasing time of drying however, increasing mass and drying time moisture removal was not increased upto a noticeable extent.

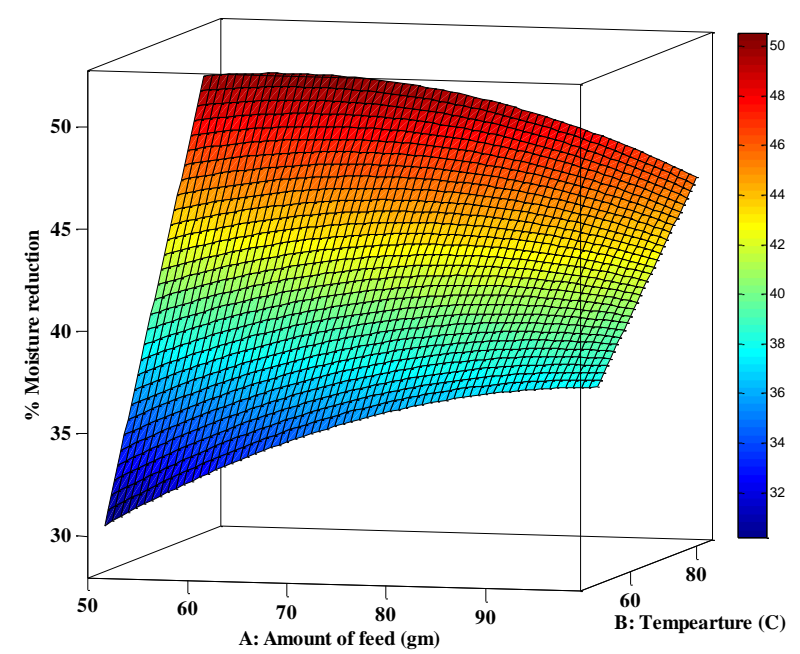

Figure 3 Response of moisture reduction with variation of amount of corn kernels and drying temperature.

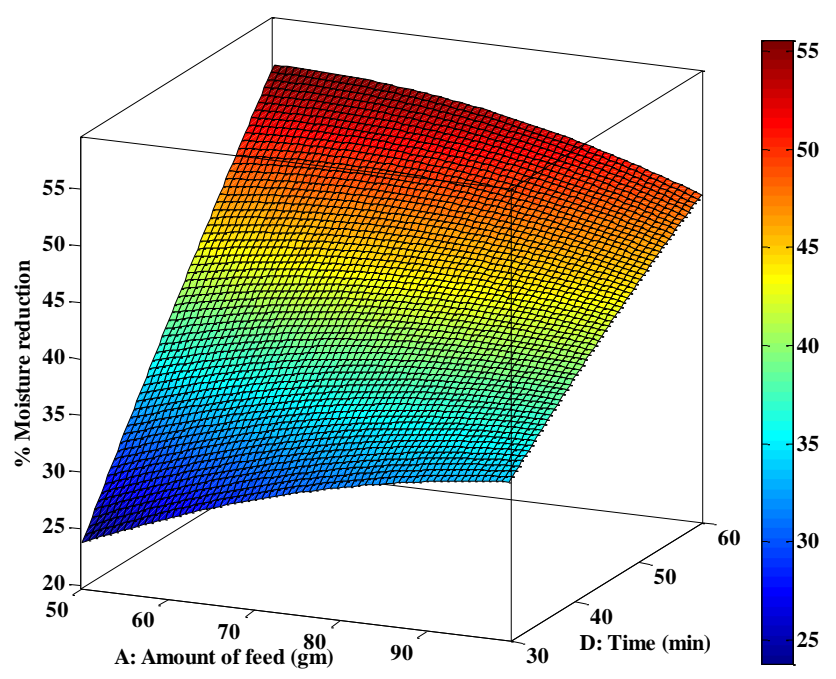

Figure 4 Response of moisture reduction with variation of amount of corn kernels and drying time.

Fig 5 shows the effect of drying time and temperature of hot air for a constant mass of corn kernels on moisture removal. For the minimum time and temperature $30 \mathrm{~min}$ and $50{ }^{\circ} \mathrm{C}$, 
respectively, the moisture removed was only $20 \%$ of the total moisture. Moisture removal increases as the drying time and hot air temperature increases for a constant mass of corn kernels. It can be explained as the temperature of dry air induces a temperature gradient within the corn kernels and moisture removes quickly than a constant temperature (Kovács et al., 2010).

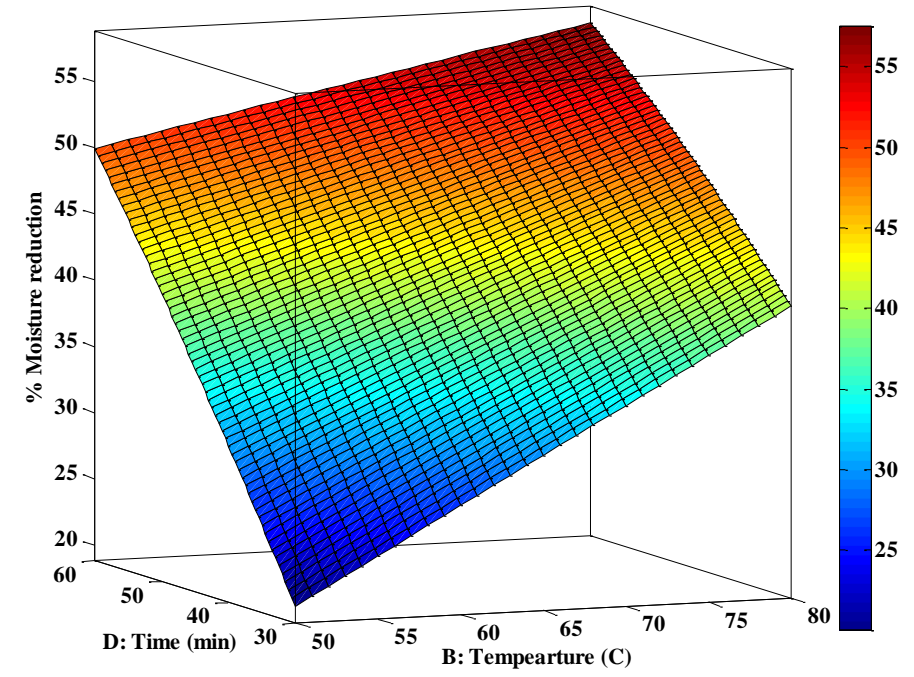

Figure 5 Response of moisture reduction with variation of drying time and drying temperature.

Figure 6 shows the effect of air velocity and hot air temperature on moisture removal. The results reveal that if both parameters were increased the moisture will be reduced at a specific temperature with increasing air velocity. Temperature alone will not be able to remove moisture if sufficient air velocity will not be provided. At this point we can see the effect of heat transfer and diffusion of air. Heat transfer alone does not remove enough moisture. The moisture removed from the surface of the kernels will be carried away by the air, with less air velocity the water vapors will be condensed in the bed itself and effective drying will not take place. Studies have been done on corn drying in fluidized bed dryer where temperature, air velocity and bed depth and fraction of air recycled were observed. It was discussed that 
increasing air velocity increases the diffusion of hot air in corn kernels. It is in agreement with the present result. ${ }^{[9]}$

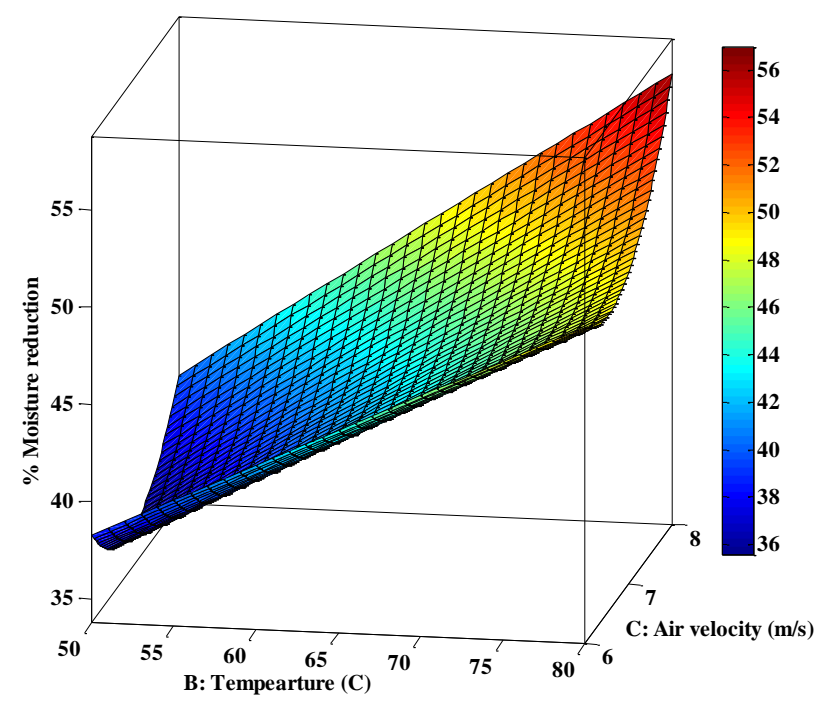

Figure 6 Response of moisture reduction with variation of drying temperature and air velocity.

For better understanding of the effect of air velocity and drying time on moisture reduction, a surface curve is plotted including all three parameters in Figure 7. A sufficient contact time of hot air to corn kernel is required to diffuse to corn surface. The result shows that if the time of contact is less and air velocity is high upto some extent the moisture is removed however, if air velocity and drying time both were increased for a particular feed amount, moisture removal was observed quite significant. 


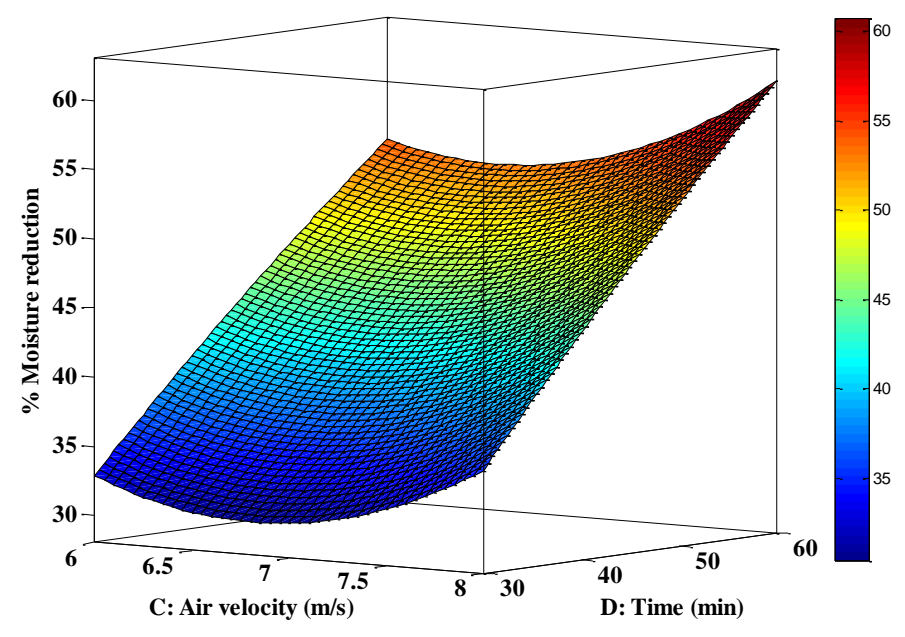

Figure 7 Response of moisture reduction with variation of drying time and air velocity.

The actual values of dryness considering all four parameters with predicted model is plotted in Figure 8. The experimental values and predicted values with regression co-efficient 0.91 shows good agreement of model with experimental values.

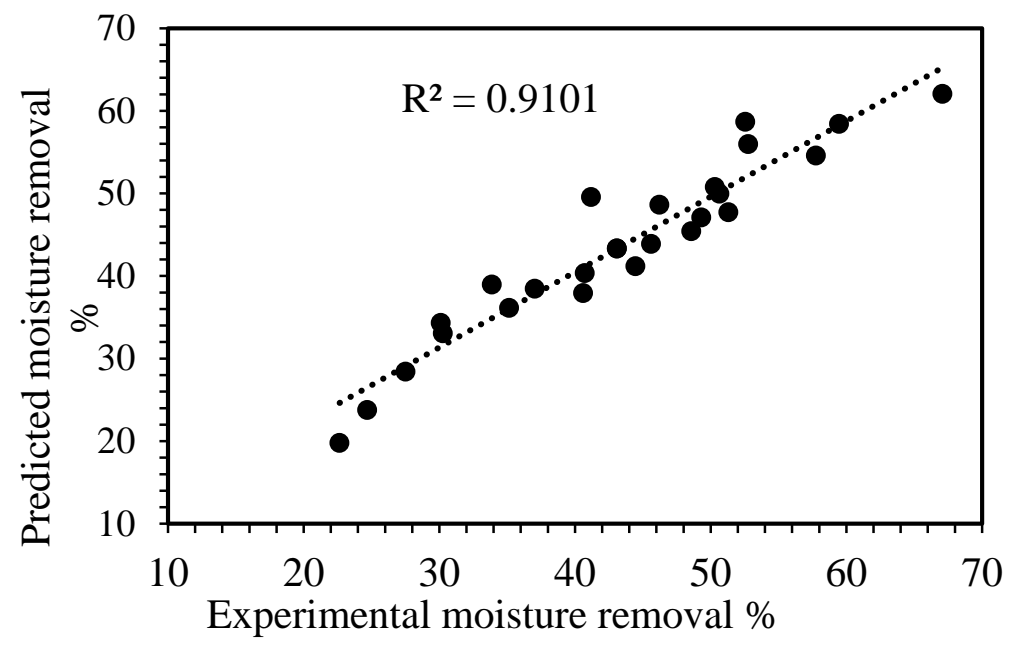

Figure 8 Comparison of experimental moisture reduction with predicted values from model equation. 
The significance of coefficients, defined in Box-Behnken design, was further evaluated and their effect on process parameters was observed. The importance of each coefficient value is defined by $P$-value and $F$-value. Table 3 shows that, for fluidized bed dryer, all linear components in the experimental model were significant $(P<0.5)$ with amount of feed and air velocity having the strongest effect on moisture removal. Coefficients of interaction of air velocity with temperature and drying time were observed positive. However, other interactions of parameters were depicted with a negative coefficient. These observations rationalized amount of feed and air velocity have the most significant effect on moisture removal. It is also confirmed with $P$ value.

Table $3 F$ and $P$ values for all coefficients by ANOVA

\begin{tabular}{|c|c|c|c|c|c|c|}
\hline Source & DF & Seq SS & Adj SS & Adj MS & $f$-value & $p$-value \\
\hline Regression & 14 & 2765.07 & 2765.07 & 197.505 & 8.41 & 0 \\
\hline Linear & 4 & 2430.76 & 319.54 & 79.884 & 3.4 & 0.044 \\
\hline $\mathbf{A}$ & 1 & 12.21 & 85.78 & 85.785 & 3.65 & 0.08 \\
\hline B & 1 & 664.09 & 9.45 & 9.447 & 0.4 & 0.538 \\
\hline $\mathbf{C}$ & 1 & 83.59 & 72.13 & 72.133 & 3.07 & 0.105 \\
\hline D & 1 & 1670.86 & 42.05 & 42.049 & 1.79 & 0.206 \\
\hline Square & 4 & 135.53 & 135.53 & 33.884 & 1.44 & 0.279 \\
\hline $\mathbf{A} * \mathbf{A}$ & 1 & 44.04 & 22.9 & 22.895 & 0.98 & 0.343 \\
\hline $\mathbf{B} * \mathbf{B}$ & 1 & 12.86 & 2.16 & 2.155 & 0.09 & 0.767 \\
\hline $\mathbf{C} * \mathbf{C}$ & 1 & 77.95 & 64.78 & 64.779 & 2.76 & 0.123 \\
\hline D*D & 1 & 0.68 & 0.68 & 0.683 & 0.03 & 0.867 \\
\hline Interaction & 6 & 198.77 & 198.77 & 33.129 & 1.41 & 0.287 \\
\hline$A * B$ & 1 & 54.66 & 54.66 & 54.656 & 2.33 & 0.153 \\
\hline $\mathbf{A} * \mathbf{C}$ & 1 & 2.07 & 2.07 & 2.074 & 0.09 & 0.771 \\
\hline A*D & 1 & 72.29 & 72.29 & 72.293 & 3.08 & 0.105 \\
\hline B*C & 1 & 22.74 & 22.74 & 22.74 & 0.97 & 0.344 \\
\hline B*D & 1 & 42.18 & 42.18 & 42.181 & 1.8 & 0.205 \\
\hline C*D & 1 & 4.83 & 4.83 & 4.828 & 0.21 & 0.658 \\
\hline Residual Error & 12 & 281.71 & 281.71 & 23.476 & & \\
\hline Lack-of-Fit & 10 & 281.71 & 281.71 & 28.171 & * & $*$ \\
\hline
\end{tabular}




\section{MODEL VALIDATION}

The objective of the present study was to optimize the batch drying in a fluidized bed dryer using Box-Behnken design. It has been observed that all parameters have an effect in drying of corn kernels. MATLAB has been used to optimize different parameters and to get an optimum response between maximum and minimum limit of parameters. The parameters 50 gm of corn kernels, $80{ }^{\circ} \mathrm{C}$ drying temperature, $8 \mathrm{~m} / \mathrm{sec}$ velocity of air, and $60 \mathrm{~min}$ time of drying can remove $73.3 \%$ of moisture. A confirmation of experiments has been performed in triplicate based on predicted and shows $\pm 3 \%$ error. This indicates that Box Behnken design in conjunction with ANOVA can be applied efficiently to optimize the design of experiments for drying of corn kernels.

\section{CONCLUSION}

The optimal levels of different operating parameters with the help of Box-Behnken design were calculated to dry a particular amount of corn kernel. The response surface methodology provides a relationship among the parameters which can be utilized in finding optimal values. The three level factorial Box-Behnken experimental design model was investigated for four variables namely: amount of feed, drying temperature, drying time, and velocity of hot air. For a particular feed, increasing other three parameters increase moisture reduction however increasing amount of feed with three other parameters reaches a maximum and then decreases.

The model equation was obtained with experimental results as an initial guess and error was minimized. MATLAB 7.1 software was used to model the equation. Predicted values of $y_{d}$ were in good agreement with the experimental results in the range of $R^{2}$ value of 0.91 . The 
parameters considered for drying of corn kernels like amount of feed and air velocity were not observed in literature. The studies were more focused on drying time however the parameters all together affect moisture removal overall as seen in results. Using surface response technique one can find optimum conditions for drying of corn kernel easily. This paper shows that this technique is economical as well as less time consuming.

\section{REFERENCES}

Doymaz, I. 2009. Thin-layer drying of spinach leaves in a convective dryer, Journal of Food Process Engineering. 32(1): 112-125.

Giner, S. A., Calvelo, A., 1987. Modelling of Wheat Drying in Fluidized Beds. Journal of Food Science. 52 (5): 1358-1363.

Inaba, H., Aoyama, S., Haruki, N., Horibe, A., Nagayoshi, K., 2002. Heat and mass transfer characteristics of air bubbles and hot water by direct contact. Heat and Mass Transfer. 38: 449-457.

Kovács, A., Lakatos, E., Milics, G., Neményi, M., 2010. Finite Element Modeling of Coupled Heat and Mass Transfer of a Single Maize Kernel Based on Water Potential Using COMSOL Multiphysics Simulation, Proceedings of the COMSOL Conference, Paris.

Mathekar, R., Agrawal, S., 2017. Mathematical modelling for heat and mass transfer during convective drying of pumpkin. Food and Bioproducts Process. 101: 68-73. 
Malumba, P., Janas, S., Masimango, T., Sindic, M., Deroanne, C., Be'Ra F., 2009. Influence of drying temperature on the wet-milling performance and the proteins solubility indexes of corn kernels. Journal of Food Engineering. 95 (3): 393-399.

Momenzadeh, L., Zomorodian, A., Mowla, D, 2011. Experimental and theoretical investigation of shelled corn drying in a microwave-assisted fluidized bed dryer using Artificial Neural Network. Food Bioproduction and Processes. 89(1): 15-21.

Nawirska, A., Figiel, A., Kucharska, A. Z., Sokół-Ł_etowska, A., Biesiada, A., 2009. Drying kinetics and quality parameters of pumpkin slices dehydrated using different methods Journal of Food Engineering. 94: 14-20.

Nonhebel, G., Moss, A. A. H., 1971. Drying of solids in the chemical industry. Butterworth, London.

Owolade, O. F., Alabi, B. S., Enikuomehin, O.A., Atungwu, J. J., 2005. Effect of harvest stage and drying methods on germination and seed-borne fungi of maize (Zea mays L.) in South West Nigeria. African Journal of Biotechnology. 4 (12): 1384-1389.

Sahdev, R K., Kumar, M., Dhingra, A K., 2017. Effect of mass on convective heat transfer coefficient during open sun drying of groundnut. Journal of Food Science and Technology. 54 (13): 4510-4516.

Soponronnarit, S., Pongtornkulpanich, A., Prachayawarakorn, S., 1997. Drying characteristic of corn in fluidized bed dryer. Drying Technology. 15 (5): 1603-1615.

Singh, T., Awasthi, A., Tripathi, P., Gautam, S., Gautam, A., 2016. Grinding analysis of Indian coal using response surface methodology. International Journal of Coal Science and Technology. 3 (2) 184-190.

Zahoor, U., Saowapa J., Waraporn B., 2016. Effect of air temperature and velocity on moisture diffusivity in relation to physical and sensory quality of dried pumpkin seeds, Drying Technology. 34 (12): 1423-1433. 
Zhang, Q., Litchfield, J.B., 1991. An optimization of intermittent corn drying in a laboratory scale thin layer dryer. Drying Technology. 9 (2): 383-395. 